\title{
Reward magnitude effects as a function of within-day trial-by-trial analysis
}

\author{
STEPHEN F. DAVIS \\ Emporia State University, Emporia, Kansas 66801 \\ and \\ JOHN D. SEAGO \\ Concord College, Athens, West Virginia 24712
}

\begin{abstract}
Two groups of rats received 112 large- or small-reward training trials, respectively, in a straight runway. Trials were administered at the rate of four per day. A comparison of withinday trial-by-trial analyses, performed over the last 6 days of training, indicated that the occurrence (or lack) of reward magnitude effects was a function of which daily trials were analyzed.
\end{abstract}

Tarpy and Mayer (1978) suggest that "many experiments have indicated that reward learning is positively related to the size of the reinforcement" (p. 65). Likewise, Ellis, Bennett, Daniel, and Rickert (1979) indicate that "the amount of reward is considered to be an important variable in both the associative and the motivational interpretation of reinforcement" (p. 44). On the other hand, Ellis et al. (1979) are quick to point out that "recently a number of studies. . . have challenged the generalization that reward magnitude determines asymptotic level" (p. 45). For example, Black (1969), Campbell, Batsche, and Batsche (1972), McCain (1970), McCain, Dyleski, and McElvain (1971), and McCain, Ward, and Lobb (1976) have reported a collapse or dissipation of large- vs. small-reward performance differences. Further, this collapse has been most evident in studies employing extended training. On the other hand, studies reporting asymptotic differences have also been reported recently (e.g., Daly, 1972; Davis, Prytula, \& Seago, 1976).

This current research on reward magnitude effects has resulted in a renewed interest in the delineation of the relevant factors involved. For example, such factors as satiation (Campbell et al., 1972), single- vs. multiplepellet rewards (Daly, 1972; McCain, 1969), rate of approach to asymptote (McHose \& Moore, 1976), preexperimental diet (Prytula, Davis, \& Voorhees, 1978), and the particular segment of the instrumental response chain that is measured or reported (Davis et al., 1976) have been shown to be related to the development and/or collapse of reward magnitude effects. In reviewing these apparently divergent results, as well as 11 large- vs. small-reward comparisons from their own laboratory, McHose and Moore (1976) note one consistent point of agreement: The rate of approach to asymptote appears to be positively related to reward magnitude.

In order to administer the relatively large number of training trials that appear to be required to produce the collapse or dissipation of reward magnitude effects, it is not uncommon to find that multiple daily trials have been administered (e.g., Davis, Harper, \& Seago, 1975; McCain, Boodee, \& Lobb, 1977; McCain, Lobb, \& Newberry, 1976). Such trial-administration procedures may well produce a "warm-up" effect, with performance on the initial trial(s) being inferior to that shown on later trials. As some average measure of daily performance, for example, median performance (McCain, Lobb, \& Newberry, 1976) or mean speed (Davis et al., 1976; McHose \& Moore, 1976; Prytula et al., 1978) is typically reported, the possibility that unique trial-by-trial effects are obscured in such cases appears genuine. The present experiment was conducted to specifically evaluate the relationship between reward magnitude effects and specific within-day trials.

\section{METHOD}

\section{Subjects}

Twenty 90-day-old male Holtzman rats served as subjects. All subjects were housed in individual cages with water freely available. One week prior to the start of pretraining, all subjects were put on a deprivation regimen and maintained at $85 \%$ of their free-feeding body weights.

\section{Apparatus}

A single straight runway $(11.43 \mathrm{~cm}$ wide and $12.70 \mathrm{~cm}$ high) with a gray startbox and black run and goal sections served as the experimental apparatus. The startbox was separated from the $91.44-\mathrm{cm}$ run section by a Masonite guillotine door. A second Masonite door separated the run section from a $30.40-\mathrm{cm}$ goalbox. Lifting the start door activated a Standard electric timer; interrupting a photobeam $15.24 \mathrm{~cm}$ beyond the start door stopped the first timer (start time) and activated a second timer. Interrupting a second photobeam $76.20 \mathrm{~cm}$ beyond the first photobeam stopped the second timer (run time) and started a third timer. Interrupting a third photobeam located $5.08 \mathrm{~cm}$ in front of a recessed goal cup stopped the third timer (goal time). The entire apparatus was covered with $.64-\mathrm{cm}$ hardware cloth and was floored with wood. 


\section{Procedure}

Prior to pretraining, the subjects were randomly assigned to two groups, $S$ and $L$, of 10 subjects each.

A pretraining period of 4 days preceded the start of the experiment. During the first 2 days, all subjects were handled and tamed for $1 \mathrm{~min}$ each and were habituated to the $45-\mathrm{mg}$ Noyes reward pellets in the home cage. On each of the last 2 days of pretraining, each subject received a 5-min exploration period in the unbaited runway.

Experimental testing lasted 28 days. During this period, each subject received 112 trials at the rate of 4 trials/day. During experimental testing, subjects in Group S received 145-mg Noyes pellet per trial, and subjects in Group $L$ received 12 45-mg Noyes pellets per trial. The order for running subjects was randomized daily, but it was constant from trial to trial within days. Maintenance of the deprivation regimen took place after all subjects had completed their daily session.

\section{RESULTS AND DISCUSSION}

Prior to analysis, all latencies were reciprocated and multiplied by the appropriate constant to yield speed scores in meters per second. Since the persistence and dissipation of magnitude effects during the terminal stages of the 112-trial training period were of major importance, the last 6 days of training ( 24 trials) were selected for graphing and analysis purposes. To ascertain specific within-day effects, separate analyses of variance comparing Groups S and L were performed for Trial 1, the average of Trials 2 and 3, Trial 4, and the average speeds for Trials 14 . The results of these analyses will be considered individually.

\section{Trial 1}

Mean start, run, and goal speeds for Trial 1 are shown in Figure 1. Analysis of variance failed to yield any significant Trial 1 effects.

\section{Trials 2-3}

Figure 2 shows the mean start, run, and goal speeds for Groups $\mathrm{S}$ and $\mathrm{L}$ for the average of Trials 2 and 3. Start and goal measure analyses yielded significant reward magnitude effects [start, $F(1,18)=9.63, \mathrm{p}<.01$; goal, $\mathrm{F}(1,18)=4.58, \mathrm{p}<.05]$.

\section{Trial 4}

Figure 3 shows the mean start, run, and goal speeds for Groups $S$ and $L$ for Trial 4. Significant reward magnitude effects were found in all three measures [start, $\mathrm{F}(1,18)=11.52, \mathrm{p}<.01 ;$ run, $\mathrm{F}(1,18)=5.35, \mathrm{p}<.05$; goal, $\mathrm{F}(1,18)=8.33, \mathrm{p}<.01]$.

\section{Trials 1-4}

Group mean start, run, and goal speeds for the average of Trials 1.4 are shown in Figure 4. Analysis of variance indicated that reward magnitude effects were significant in the start $[\mathrm{F}(1,18)=10.07, \mathrm{p}<.01]$ and goal $[F(1,18)=6.67, p<.05]$ measures.

Obviously, different impressions regarding the effectiveness of reward magnitude in producing performance differences can be created by the present data. Had Trial 1 been emphasized, a strong case for the lack of

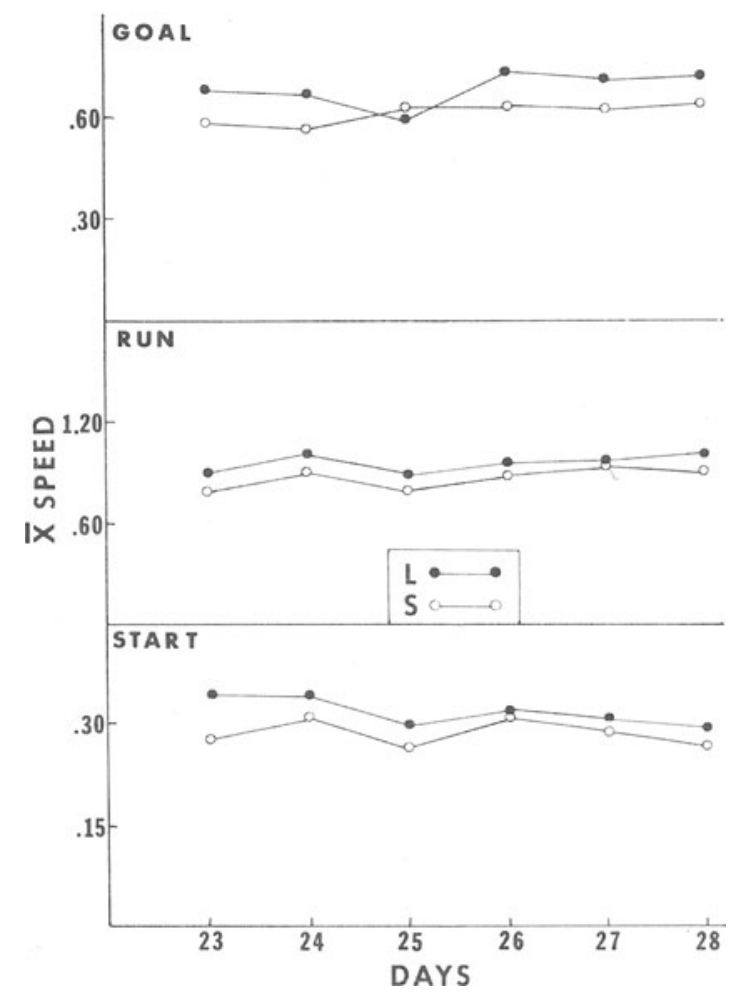

Figure 1. Trial 1: mean start, run, and goal speeds for Groups $S$ and $L$ for the last 6 days ( 24 trials) of training.



Figure 2. Trials 2 and 3: mean start, run, and goal speeds for Groups $S$ and $L$ for the last 6 days ( 24 trials) of training. 




Figure 3. Trial 4: mean start, run, and goal speeds for Groups $S$ and $L$ for the last 6 days ( 24 trials) of training.

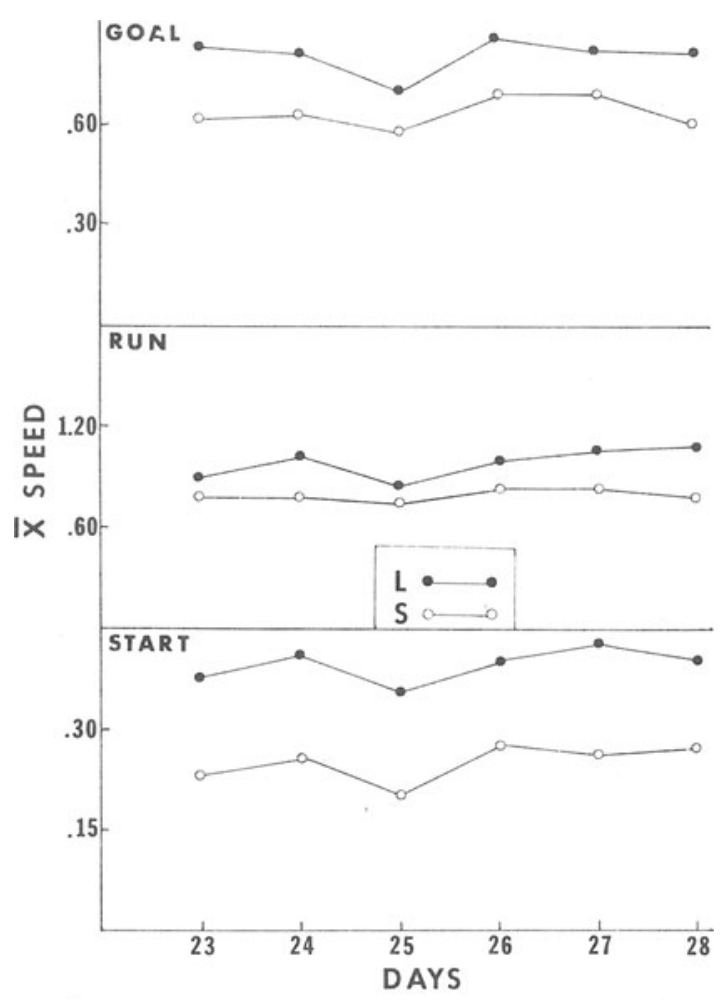

Figure 4. Trials 1-4: mean start, run, and goal speeds for Groups $S$ and $L$ for the last 6 days ( 24 trials) of training. such effects could well be mustered. This is to be contrasted with the significant effects shown in all measures when Trial 4 was analyzed separately. On the other hand, significant $S$ and $L$ differences were shown only in the start and goal measures when the averages of Trials 2 and 3 and the average of all daily trials were analyzed.

Rather than resolving or clarifying issues, the present data may serve to increase the complexity in this area. In addition to such factors as single- vs. multiple-pellet rewards (see Daly, 1972; McCain, 1969), possible satiation effects (Campbell et al., 1972), particular aspect or segment of the instrumental response that is reported (Davis et al., 1976), number of acquisition trials administered (Davis et al., 1976; McCain, 1970), and type of data subjected to analysis (see Traupmann \& Wong, 1971), it now appears relevant to consider which trials are reported in those cases involving the administration of multiple daily trials. Obviously, the traditional and possibly simplistic view that larger reward magnitudes result in faster acquisition and/or higher asymptotic performance levels must be tempered to take into account this increasing list of relevant parameters.

\section{REFERENCES}

BLACK, R. W. Incentive motivation and the parameters of reward in instrumental conditioning. In W. J. Arnold \& D. Levine (Eds.), Nebraska Symposium on Motivation. Lincoln: University of Nebraska Press, 1969.

Campbell, P. E., Batsche, C. J., \& Batsche, G. M. Spacedtrials reward magnitude effects in the rat: Single versus multiple food pellets. Journal of Comparative and Physiological Psychology, 1972, 18, 360-364.

DALY, H. B. Learning to escape cues paired with reward reductions following single- or multiple-pellet rewards. Psychonomic Science, 1972, 26, 49-52.

Davis, S. F., Harper, W. E., \& Seago, J. D. Runway performance of normal, sham, and anosmic rats as a function of magnitude of reward and magnitude shifts. Bulletin of the Psychonomic Society, 1975, 6, 367-369.

Davis, S. F., Prytula, R. E., \& Seago, J. D. Hey Garvin! Science is a game: A reply to McCain, Ward, and Lobb. Bulletin of the Psychonomic Society, 1976, 7, 93-95.

Ellis, H. E., Bennett, T. L., Daniel, T. C., \& Rickert, E. J. Psychology of learning and memory. Monterey, Calif: Brooks/ Cole, 1979.

McCaIn, G. Different levels of performance with equivalent weights of reward. Psychonomic Science, 1969, 14, 2-3.

McCaIn, G. Reward magnitude and instrumental responses: Consistent and partial reward. Psychonomic Science, 1970, 19, 139-141.

McCain, G., Boodee, A., \& Loвb, M. Extended training: Delay of reward. Bulletin of the Psychonomic Society, 1977, 9, 111-112.

McCain, G., Dyleski, K., \& McElvain, G. Reward magnitude and instrumental responses: Consistent reward. Psychonomic Monograph Supplements, 1971, 3(16, Whole No. 48).

McCain, G., Lobb, M., \& Newberry, J. Extended training and multiple shifts: Percentage of reward. Bulletin of the Psychonomic Society, 1976, 8, 191-193.

McCAIn, G., WARD, R., \& LoвB, M. Reward magnitude and a comment. Bulletin of the Psychonomic Society, 1976, 7, 90-92.

McHose, J. H., \& Moore, J. N. Reinforcer magnitude and instrumental performance in the rat. Bulletin of the Psychonomic Society, 1976, 8, 416-418. 
Prytula, R. E., Davis, S. F., \& Voorhees, J. W. The effects of preexperimental diet upon reward magnitude effects. Bulletin of the Psychonomic Society, 1978, 11, 117-119.

TARPY, R. M., \& MAYER, R. E. Foundations of learning and memory. Glenview, Ill: Scott, Foresman, 1978.
Traupmann, K. L., \& Wong, P. T. P. Reward magnitude and instrumental responses: A comment. Psychonomic Science, 1971, 23, 13-14.

(Received for publication September 17, 1980.) 